\title{
Review \\ Bench-to-bedside review: Appropriate antibiotic therapy in severe sepsis and septic shock - does the dose matter?
}

\author{
Federico Pea ${ }^{1}$ and Pierluigi Viale ${ }^{2}$
}

\author{
${ }^{1}$ Institute of Clinical Pharmacology \& Toxicology, Department of Experimental and Clinical Pathology and Medicine, Medical School, University of Udine, \\ 33100 Udine, Italy \\ ${ }^{2}$ Clinic of Infectious Diseases, Department of Medical and Morphological Research, Medical School, University of Udine, 33100 Udine, Italy
}

Corresponding author: Federico Pea, pea.federico@aoud.sanita.fvg.it

Published: 10 June 2009

This article is online at http://ccforum.com/content/13/3/214

(c) 2009 BioMed Central Ltd
Critical Care 2009, 13:214 (doi:10.1186/cc7774)

\begin{abstract}
Appropriate antibiotic therapy in patients with severe sepsis and septic shock should mean prompt achievement and maintenance of optimal exposure at the infection site with broad-spectrum antimicrobial agents administered in a timely manner. Once the causative pathogens have been identified and tested for in vitro susceptibility, subsequent de-escalation of antimicrobial therapy should be applied whenever feasible. The goal of appropriate antibiotic therapy must be pursued resolutely and with continuity, in view of the ongoing explosion of antibiotic-resistant infections that plague the intensive care unit setting and of the continued decrease in new antibiotics emerging. This article provides some principles for the correct handling of antimicrobial dosing regimens in patients with severe sepsis and septic shock, in whom various pathophysiological conditions may significantly alter the pharmacokinetic behaviour of drugs.
\end{abstract}

\section{Introduction}

During the last half decade of the 20th century, several major studies conducted in critically ill patients in both Europe and the USA demonstrated unequivocally that initial inappropriate antimicrobial treatment for pneumonia was associated with increased mortality [1]. It is of note that both in these earlier studies and in subsequent confirmatory ones [2,3], the appropriateness of treatment was typically assessed in terms of antimicrobial coverage, defined as the use of an agent to which a pathogen is susceptible [4]. In contrast, less attention - if any - was given to the fact that failures of anti-infective therapy in the intensive care unit (ICU) setting might occur not only as a consequence of inappropriate choice but also with inappropriate dosing, potentially leading to suboptimal exposure to the broad-spectrum antimicrobial agent at the infection site, even if it is administered in a timely manner [5].
The issue of dosing is of particular relevance in patients with severe sepsis or septic shock, in whom various pathophysiological conditions may significantly alter the pharmacokinetic behaviour of drugs [6]. Importantly, pharmacokinetic studies to define drug dosages for regulatory purposes are usually carried out in healthy volunteers, who by definition are not patients. Consequently, it is not surprising that dosing regimens of several antimicrobials are expected to be significantly different in ICU patients from those suggested for clinically stable patients.

\section{The concept of the antimicrobial therapy puzzle}

A recent study assessed the outcomes of bacteraemia due to Pseudomonas aeruginosa according to antimicrobial choice and to piperacillin-tazobactam susceptibility in two parallel retrospective cohorts [7]. It offers an opportunity to raise some interesting observations on this topic. The first cohort included 34 patients with bacteraemia due to $P$. aeruginosa with borderline susceptibility to piperacillin-tazobactam (minimum inhibitory concentrations [MICs] of 32 or $64 \mathrm{mg} / \mathrm{l})$. In this cohort the 30-day mortality rate was significantly higher among those patients empirically treated with this antibiotic $(n=7)$ than in those treated with other effective antipseudomonal antimicrobials $(n=27 ; 85.7 \%$ versus $22.2 \%$, $P=0.004)$. Conversely, in the second cohort, which included 49 patients with bacteraemia due to bacterial isolates that were more susceptible to piperacillin-tazobactam (MICs $\leq 16 \mathrm{mg} / \mathrm{l})$, the mortality rate was not statistically different between piperacillin-tazobactam and control groups $(30.0 \%$ versus $20.5 \%, P=0.673$ ).

$\mathrm{APACHE}=$ Acute Physiology and Chronic Health Evaluation; $\mathrm{AUC}=$ area under the plasma concentration-time curve; $\mathrm{C}_{\max }=$ peak plasma concentration; $\mathrm{CL}_{\mathrm{Cr}}=$ creatinine clearance; $\mathrm{C}_{\min }=$ plasma trough concentration; CRRT = continuous renal replacement therapy; $\mathrm{C}_{\mathrm{t}}=$ target plasma concentration; ICU = intensive care unit; $\mathrm{LD}=$ loading dose; $\mathrm{MIC}=$ minimum inhibitory concentration; $\mathrm{TDM}=$ therapeutic drug monitoring; $\mathrm{t}>\mathrm{MIC}=$ time for which the antibiotic concentration exceeds the MIC; VAP $=$ ventilator-associated pneumonia; $V_{d}=$ volume of distribution. 
Although this study poses an interesting question about the necessity of reducing the microbiological breakpoints for piperacillin-tazobactam, several aspects deserve some consideration [7]. First, details of drug dosages were not provided. There is evidence that standard dosages of piperacillin ( $4 \mathrm{~g}$ given over 30 minutes every 6 hours), by ensuring very low trough plasma levels, may not be sufficient in ICU patients with enhanced renal function [8], and this suggests that drug dosage may be a major issue in this setting.

Second, clinical outcome was not related to the immunological status of the patients. In this regard, the efficacies of two different administration schedules of ceftazidime were compared in an interesting experimental animal model of pneumonia due to Klebsiella pneumoniae [9]. In immunocompetent animals the dose needed to ensure that $50 \%$ of the rats survived was similar for both continuous infusion and intermittent infusion every 6 hours $(0.36$ versus $0.35 \mathrm{mg} / \mathrm{kg}$ ). In contrast, in immunocompromised animals the $50 \%$ protective dose was 15-fold lower when using continuous infusion, even if higher doses for both administration schedules were needed (1.52 mg/kg versus $24.37 \mathrm{mg} / \mathrm{kg}$ ). This study supports the general contentions that the immunological status of the patient may be relevant to infection response and that continuous infusion may be especially helpful for improving the efficacy of $\beta$-lactams in immunocompromised patients [10].

Finally, in that study [7] it was clearly stated that no patient received the drug by prolonged or continuous infusion. However, in vivo experiments have shown that bacterial killing with penicillins is slow and may become maximal when the time for which the antibiotic concentration exceeds the MIC of the infecting pathogen ( $\mathrm{t}>\mathrm{MIC}$ ) is equal to $50 \%$ to $60 \%$ of the dosing interval [11]. Of note, a recent Monte Carlo simulation study assessed the theoretical cumulative fractions of response with the standard $16 / 2 \mathrm{~g}$ daily dosage of piperacillin/tazobactam for the treatment of $P$. aeruginosa infections (with a target $\mathrm{t}>\mathrm{MIC}$ of $50 \%$ ), according to different administration schedules [12]. The percentage of response was increased by about 10\% when simulating 3-hour prolonged infusion or continuous infusion in comparison with 30-minute intermittent infusion (around 90\% versus $80 \%$ ). This suggests that, under the same daily dose, extended infusion or continuous infusion - by ensuring more sustained trough levels - may be worthwhile in terms of increasing the clinical efficacy of time-dependent antimicrobials.

From these considerations, it becomes evident that in order to optimize antibiotic therapy in critically ill patients it is not sufficient to make the correct choice on the basis of the antibiogram. It is also mandatory to consider timely administration of the right dose at the right schedule, according to the pathophysiological and immunological status of the patient.

Otherwise stated, the benefit of administering the correct antibiotic choice in terms of spectrum of activity can be
Figure 1

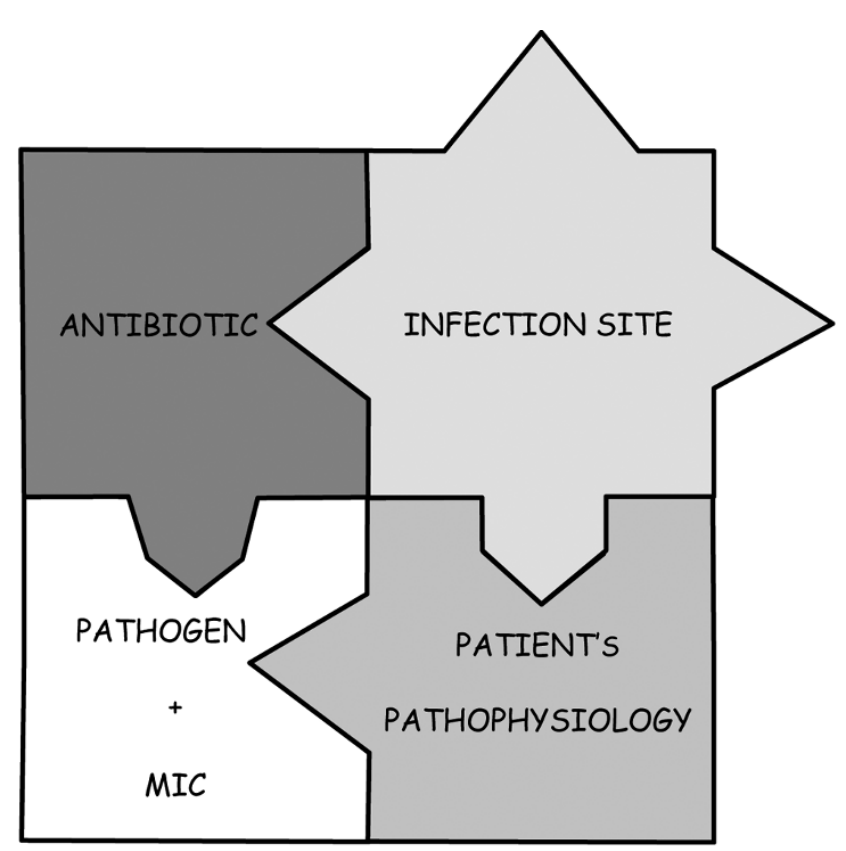

The antimicrobial therapy puzzle. MIC, minimum inhibitory concentration. Reproduced with permission from Pea and Viale [5].

nullified by delayed treatment or insufficient dosing, and this is to be avoided. Indeed, it should not be overlooked that assessment of the in vitro bacterial susceptibility is but one of the pieces needed to solve correctly the 'antimicrobial therapy puzzle' (Figure 1) [5]. Particular attention should also be given to the infection site. Drug penetration into infected tissues may be affected by the peculiar pharmacokinetic properties of antimicrobials (Figure 2). Given that similar antibiotics may have very different diffusion profiles, knowledge of antibiotic concentration at the site of infection is of paramount importance in terms of optimizing antimicrobial therapy in patients with severe sepsis. As a general rule, hydrophilic antimicrobials, as opposed to lipophilic ones, may diffuse only slowly and partially in deep-seated infection sites. Overall, this appears to support the view that dosages higher than needed for the treatment of bacteraemia and/or improved administration schedules are needed to treat deepseated infections (such as pneumonia and intra-abdominal infections), with hydrophilic antimicrobials to ensure optimal pharmacodynamic exposure at the infection site $[5,13,14]$. Moreover, it should be borne in mind that drugs with excellent in vitro activity against multiresistant pathogens may be inactivated at the infection site, as in the case of daptomycin, which is not applicable to lung infections because of its inactivation by pulmonary surfactant [15]. Finally, drug concentrations at sites of infection may be affected also by the pathophysiological setting, which may change significantly in patients with severe sepsis even during the brief period of a few hours $[5,16]$. 
Hydrophilic antibiotics

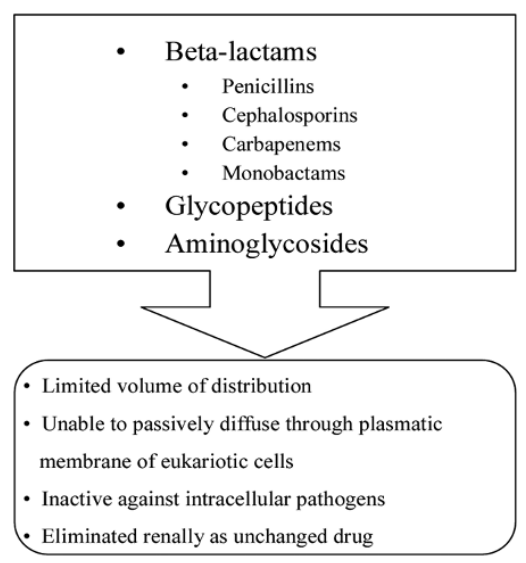

Lipophilic antibiotics

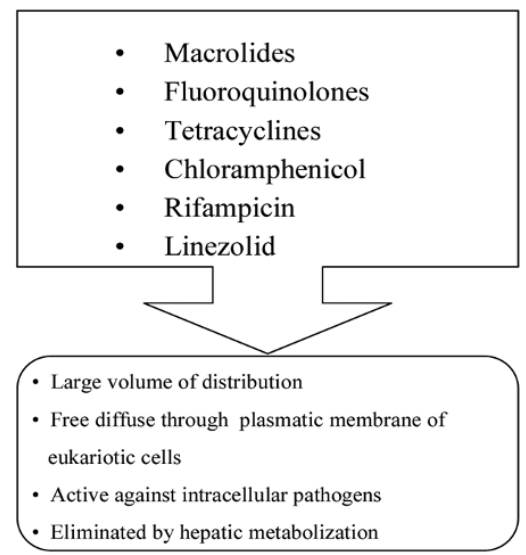

Classification of antimicrobials according to their solubility and pharmacokinetic/pharmacodynamic properties. Reproduced and adapted with permission from Pea and colleagues [6] and from Pea and Viale [5].

\section{Specific pathophysiological and pharmacokinetic/pharmacodynamic characteristics in critically ill patients with severe sepsis/septic shock}

Recent international guidelines for the management of severe sepsis and septic shock (Surviving Sepsis Campaign) [16] included three important recommendations about antimicrobial therapy: always begin intravenous antibiotics within the first hour after severe sepsis and septic shock are recognized; use broad-spectrum agents with good penetration into the presumed site of infection; and reassess the antimicrobial regimen daily to optimize efficacy, prevent resistance, avoid toxicity and minimize costs. Adherence to these recommendations requires an awareness that drug pharmacokinetics in critically ill patients may undergo significant changes because of the pathophysiology of sepsis [6].

Regarding the optimal dosage to start antimicrobial therapy, it must be considered that the target plasma concentration $\left(\mathrm{C}_{t}\right)$ that is achieved with the first dose - loading dose (LD) depends solely on the volume of distribution $\left(\mathrm{V}_{d}\right)$ of the drug $\left(L D=C_{t} \times V_{d}\right)$. Of note, capillary leakage and fluid resuscitation [17], by expanding the extracellular fluid contents, may enlarge the $V_{d}$ of antimicrobials in patients with severe sepsis and septic shock, such that $C_{t}$ may be decreased when using the standard LD [6].

As a general rule, this 'dilution effect', the so-called 'third spacing' phenomenon, is much more relevant in hydrophilic agents such as $\beta$-lactams, aminoglycosides and glycopeptides, which selectively distribute to the extracellular space (Figure 2). Joukhadar and coworkers [18] showed that the peak levels and area under the plasma concentration-time curve (AUC) of piperacillin after a single standard $4 \mathrm{~g}$ intravenous dose were several fold lower, either in plasma or in the interstitium of soft tissues, in patients with septic shock than in correctly matched healthy volunteers. Likewise, the initial peak plasma concentrations of gentamycin and tobramycin following a $3 \mathrm{mg} / \mathrm{kg}$ LD in critically ill surgical patients with life-threatening Gramnegative infections were found to be lower than desired $(<8.3 \mathrm{mg} / \mathrm{l})$ in about half of the patients, and greater LDs - by at least $20 \%$ to $25 \%$ - were advocated [19]. Therefore, higher than standard LDs of $\beta$-lactams, aminoglycosides or glycopeptides should be administered to ensure optimal exposure at the infection site whenever treatment is begun in patients with severe sepsis or septic shock.

Importantly, the need for appropriate loading at the commencement of therapy is independent of the patient's renal function. This means that initial loading is especially important in order to avoid the risk of underexposure with renally excreted drugs that have a very long elimination halflife. For instance, in the absence of loading, several days may be required to achieve therapeutically effective concentrations of teicoplanin. We conducted a retrospective study in which therapeutic drug monitoring (TDM) results were analyzed in critically ill patients over a 7-year period in our hospital [20]. We observed that within the first 4 days of therapy, appropriate LDs of teicoplanin $(400 \mathrm{mg}$ every 12 hours at least three times) were administered to only onethird of patients (78 out of 202). Interestingly, the percentage of patients receiving appropriate loading was inversely correlated with their degree of renal function, decreasing from $60.4 \%$ in the case of normal renal function to $26.8 \%$ and $5.5 \%$, respectively, in cases of moderately or totally impaired renal function. The resulting suboptimal concentrations $(<10 \mathrm{mg} / \mathrm{l})$, persisting in most of the patients at day 4 of treatment, could have negatively affected outcomes with teicoplanin. 
Conversely, for lipophilic antibiotics (fluoroquinolones, macrolides, tetracyclines, chloramphenicol, rifampicin and oxazolidinones) the 'dilution effect' in the extracellular fluids during severe sepsis may be mitigated by the rapid redistribution of the drug to the interstitium from the intracellular compartment, which acts as a reservoir, such that the decrease in $C_{t}$ after standard dosages should be less relevant [6]. Interestingly, it was recently shown that - compared with healthy volunteers the severity of sepsis had no substantial effect in terms of decreasing the peak plasma concentration $\left(\mathrm{C}_{\max }\right)$ and $A U C$ of a lipophilic agent, namely linezolid, after a single $600 \mathrm{mg}$ standard dose [21]. This was the case both in plasma and in the interstitium of soft tissues, although a high inter-individual variability was observed. On this basis, it may be speculated that, in contrast to observations with hydrophilic antimicrobials, standard dosages of lipophilic antimicrobials may frequently ensure adequate loading even in patients with severe sepsis or septic shock.

Once appropriate initial loading is achieved, it is mandatory to reassess the antimicrobial regimen daily, because the pathophysiological changes that may occur, even during a brief period of a few hours, may significantly affect drug disposition in the critically ill patients. Of note, timely and accurate correction of maintenance doses of antimicrobials that are almost completely excreted by the renal route as unchanged moiety should be based on daily assessment of renal function. This is crucial for hydrophilic antimicrobials ( $\beta$ lactams, aminoglycosides and glycopeptides) and for moderately lipophilic antimicrobials (ciprofloxacin and levofloxacin). Estimation of creatinine clearance $\left(\mathrm{CL}_{\mathrm{Cr}}\right)$ with the Cockcroft and Gault formula [22] may safely be applied to assess glomerular filtration rates in recently hospitalized patients. A recent study confirmed that during the day after admission $\mathrm{CL}_{\mathrm{Cr}}$ estimates correlated highly with $\mathrm{CL}_{\mathrm{Cr}}$ measured over 24 hours among 359 ICU patients $\left(r^{2}=0.8357\right)$ [23]. Conversely, direct measurement of $\mathrm{Cl}_{\mathrm{Cr}}$ rather than estimation should be performed for accurate assessment of glomerular filtration rate in patients with a lengthy hospital admission ( $>1$ month). In fact, overestimation of $\mathrm{CL}_{\mathrm{Cr}}$ may be expected whenever the daily output of creatinine from muscles is impaired by the degree of muscle loss that may occur when a patient is bedridden long term [23,24].

It is well known that lower than standard dosages of renally excreted drugs must be administered in the presence of impaired renal function (Table 1). Renal failure may be the consequence of myocardial depression, which can occur as sepsis progresses and which may lead to decreased organ perfusion, but it can be also precipitated by nephrotoxic drugs (vancomycin, aminoglycosides and furosemide) or iodinated contrast agents. In renal failure, the dosage of toxic antimicrobials such as aminoglycosides and vancomycin is usually reduced. However, dosage reduction is less frequently considered for $\beta$-lactam antibiotics, even though their accumulation may result in an often underdiagnosed neurological toxicity [25-27]. Indeed, drug accumulation leading to safety issues may also be the consequence of impaired renal elimination by inhibitors of tubular secretion (as in the case of probenecid with $\beta$-lactams) and/or of drugdrug pharmacokinetic interactions, which may become especially relevant for those antimicrobials that may inhibit (erythromycin or clarithromycin) cytochrome P450-mediated drug metabolism [28].

Conversely, it is less evident that higher than standard dosages of renally excreted drugs may be needed for optimal exposure in patients with glomerular hyperfiltration $[6,29]$. Of note, glomerular hyperfiltration may the consequence of inotropic agents when hypotension does not revert with fluid therapy. This increases cardiac indices [17], which in turn lead to increased renal preload and so increased renal drug clearance. Interestingly, a very recent prospective study showed that glomerular hyperfiltration (defined as $\mathrm{CL}_{\mathrm{Cr}}$ $>120 \mathrm{ml} /$ minute per $1.73 \mathrm{~m}^{2}$ ) was a relatively frequent occurrence among 89 critically ill patients [30]. The percentage of patients exhibiting glomerular hyperfiltration was $17.9 \%$ on the first morning of ICU admission, and increased to as high as 30\% during the first week of admission. We are particularly concerned about the potential role that glomerular hyperfiltration may play in increasing mortality rate from bacterial infections in critically ill patients treated with standard dosages of renally excreted antimicrobials [31]. Therefore, we recommend that ICU physicians conduct a daily reassessment of antimicrobial regimens in accordance with daily measurement of $\mathrm{CL}_{\mathrm{Cr}}$, keeping in mind that assessment of renal function not only must identify patients with renal impairment but also must identify those with glomerular hyperfiltration, in whom higher dosages of renally excreted antimicrobials may be indicated [31].

Hypoalbuminaemia is another relevant cause of underdosing in critically ill patients whenever highly protein bound antimicrobials (teicoplanin, ertapenem or ceftriaxone) are used. Hypoalbuminaemia is a frequently occurring condition in patients with severe sepsis as a consequence of increased albumin capillary escape rate through leaky endothelium or of fluid overload. By increasing the unbound fraction, hypoalbuminaemia may promote not only more extensive distribution but also greater renal clearance [6]. It has been shown that in severe hypoalbuminaemic critically ill patients the free fraction of teicoplanin may be more than doubled [32], with significantly higher elimination rate [33].

In this context there may be an increased risk for underdosing due to improved elimination of drugs $[6,30]$. Therefore, selecting higher dosages and/or alternative dosing regimens focused at maximizing the pharmacodynamics of antimicrobials might be worthwhile, with the intent being to increase clinical cure rates among critically ill patients. Indeed, different approaches should be pursued according to the type of antibacterial activity exhibited by the various antimicrobials. 
Table 1

\begin{tabular}{|c|c|c|c|c|}
\hline \multirow[b]{2}{*}{ Antibiotic } & \multicolumn{4}{|c|}{ Renal function } \\
\hline & Increased $^{a}$ & Normal & Moderately impaired & Severely impaired \\
\hline Piperacillin/tazobatam & $\begin{array}{l}16 / 2 \mathrm{~g} \mathrm{q} 24 \mathrm{~h} \mathrm{Cl}[56,57] \\
\text { or } 3.375 \text { q6h El over } \\
4 \text { hours [51] }\end{array}$ & $4 / 0.5 \mathrm{~g} \mathrm{q6h}$ & $3 / 0.375 \mathrm{~g} \mathrm{q} 6 \mathrm{~h}$ & $2 / 0.25 \mathrm{~g} \mathrm{q} 6 \mathrm{~h}$ \\
\hline Cefotaxime & $\begin{array}{l}4 \text { to } 6 \mathrm{~g} \mathrm{q} 24 \mathrm{~h} \mathrm{Cl} \mathrm{[14]} \mathrm{or} \\
2 \mathrm{~g} \mathrm{q} 4-6 \mathrm{~h}\end{array}$ & $2 \mathrm{~g} \mathrm{q} 6-8 \mathrm{~h}$ & $2 \mathrm{~g} \mathrm{q} 6-8 \mathrm{~h}$ & $1 \mathrm{~g} \mathrm{q} 6-8 \mathrm{~h}$ \\
\hline Ceftazidime & 4 to $6 \mathrm{~g} \mathrm{q} 24 \mathrm{~h} \mathrm{Cl}[55,70]$ & $2 \mathrm{~g} \mathrm{q} 8 \mathrm{~h}$ & $1 \mathrm{~g} \mathrm{q} 8-12 \mathrm{~h}$ & 0.5 to $1 \mathrm{~g} \mathrm{q} 24 \mathrm{~h}$ \\
\hline Cefepime & $\begin{array}{l}4 \text { to } 6 \mathrm{~g} \mathrm{q} 24 \mathrm{~h} \mathrm{Cl}[71] \text { or } \\
2 \mathrm{~g} \text { q8h El over } \\
3 \text { hours [72] }\end{array}$ & $2 \mathrm{~g} \mathrm{q} 8 \mathrm{~h}$ & $2 \mathrm{~g} \mathrm{q} 12 \mathrm{~h}$ & $1 \mathrm{~g} \mathrm{q} 24 \mathrm{~h}$ \\
\hline Imipenem & $\begin{array}{l}500 \mathrm{mg} \mathrm{q} 4 \mathrm{~h} \mathrm{[46]} \mathrm{or} \\
250 \mathrm{mg} \text { q3h over } \\
3 \text { hours Cl [73] }\end{array}$ & $500 \mathrm{mg} \mathrm{q} 6 \mathrm{~h}$ & $250 \mathrm{mg} \mathrm{q} 6 \mathrm{~h}$ & $250 \mathrm{mg} \mathrm{q} 12 \mathrm{~h}$ \\
\hline Meropenem & $\begin{array}{l}1 \mathrm{~g} \mathrm{q} 6 \mathrm{~h} \text { over } 6 \text { hours } \\
\mathrm{Cl}[54]\end{array}$ & $500 \mathrm{mg} \mathrm{q} 6 \mathrm{~h}$ & $250 \mathrm{mg} \mathrm{q} 6 \mathrm{~h}$ & $250 \mathrm{mg} \mathrm{q} 12 \mathrm{~h}$ \\
\hline Ertapenem & ND & $1 \mathrm{~g} \mathrm{q} 24 \mathrm{~h}$ & $1 \mathrm{~g} \mathrm{q} 24 \mathrm{~h}$ & $500 \mathrm{mg} \mathrm{q} 24 \mathrm{~h}$ \\
\hline Gentamycin & 9 to $10 \mathrm{mg} / \mathrm{kg} \mathrm{q} 24 \mathrm{~h}^{\mathrm{b}}[74]$ & $7 \mathrm{mg} / \mathrm{kg}$ q24hb $[74,75]$ & $7 \mathrm{mg} / \mathrm{kg}$ q36-48hb & 7 mg/kg q48-96hb \\
\hline Tobramycin & 9 to $10 \mathrm{mg} / \mathrm{kg} \mathrm{q} 24 \mathrm{~h}^{\mathrm{b}}[74]$ & $7 \mathrm{mg} / \mathrm{kg}$ q24hb $[74,75]$ & $7 \mathrm{mg} / \mathrm{kg}$ q36-48hb & $7 \mathrm{mg} / \mathrm{kg} q 48-96 \mathrm{~h}^{b}$ \\
\hline Amikacin & $20 \mathrm{mg} / \mathrm{kg} \mathrm{q} 24 \mathrm{~h}^{\mathrm{b}}[8,76]$ & $15 \mathrm{mg} / \mathrm{kg} \mathrm{q} 24 \mathrm{~h}^{\mathrm{b}}$ & $15 \mathrm{mg} / \mathrm{kg}$ q36-48hb & $15 \mathrm{mg} / \mathrm{kg} \mathrm{q} 48-96 \mathrm{~h}^{\mathrm{b}}$ \\
\hline Ciprofloxacin & $\begin{array}{l}600 \mathrm{mg} \mathrm{q} 12 \mathrm{~h} \text { or } \\
400 \mathrm{mg} \text { q8h [77-79] }\end{array}$ & $400 \mathrm{mg} \mathrm{q} 12 \mathrm{~h}$ & $400 \mathrm{mg} \mathrm{q} 12 \mathrm{~h}$ & $400 \mathrm{mg} \mathrm{q} 24 \mathrm{~h}$ \\
\hline Levofloxacin & 500 mg q12h [80] & 750 mg q24h [37] & $500 \mathrm{mg}$ q24h & 500 mg q48h \\
\hline Vancomycin & $\begin{array}{l}30 \mathrm{mg} / \mathrm{kg} \text { q2} 24 \mathrm{~h} \mathrm{Cl}^{\mathrm{b}} \\
{[58,61]}\end{array}$ & $500 \mathrm{mg} \mathrm{q6h^{b }}$ & $500 \mathrm{mg} \mathrm{q} 12 \mathrm{~h}^{\mathrm{b}}$ & $500 \mathrm{mg} \mathrm{q} 24-72 \mathrm{~h}^{\mathrm{b}}$ \\
\hline Teicoplanin & $\begin{array}{l}\text { LD } 12 \mathrm{mg} / \mathrm{kg} \mathrm{q} 12 \mathrm{~h} \text { for } \\
3 \text { to } 4 \text { doses; MD } 6 \mathrm{mg} / \mathrm{kg} \\
\text { q12h }[81,82]^{\mathrm{b}}\end{array}$ & $\begin{array}{l}\text { LD } 12 \mathrm{mg} / \mathrm{kg} \mathrm{q} 12 \mathrm{~h} \text { for } \\
3 \text { to } 4 \text { doses; MD } 4 \text { to } \\
6 \mathrm{mg} / \mathrm{kg} \mathrm{q} 12 \mathrm{~h}[81,83]^{\mathrm{b}}\end{array}$ & $\begin{array}{l}\text { LD } 12 \mathrm{mg} / \mathrm{kg} \mathrm{q} 12 \mathrm{~h} \text { for } \\
3 \text { to } 4 \text { doses; MD } 2 \text { to } \\
4 \mathrm{mg} / \mathrm{kg} \mathrm{q} 12 \mathrm{~h}[81,83]^{\mathrm{b}}\end{array}$ & $\begin{array}{l}\text { LD } 12 \mathrm{mg} / \mathrm{kg} \text { q } 12 \mathrm{~h} \text { for } \\
3 \text { to } 4 \text { doses; MD } 2 \text { to } \\
4 \mathrm{mg} / \mathrm{kg} \text { q24h }[81,83]^{\mathrm{b}}\end{array}$ \\
\hline Daptomycin & ND & $6 \mathrm{mg} / \mathrm{kg} \mathrm{q} 24 \mathrm{~h}$ & $6 \mathrm{mg} / \mathrm{kg} \mathrm{q} 24 \mathrm{~h}$ & $6 \mathrm{mg} / \mathrm{kg} \mathrm{q} 48 \mathrm{~h}$ \\
\hline
\end{tabular}

Data derived from Clinical Pharmacology, Gold Standard Multimedia [84] unless otherwise specified. aSuggested on the basis of some clinical and/or population pharmacokinetic studies. ${ }^{b}$ Guided by therapeutic drug monitoring. Cl, continuous infusion; El, extended infusion; LD, loading dose; MD, maintenance dose; ND, not defined; qxh, every $x$ hours.

\section{Concentration-dependent antibiotics}

Interestingly, 'hit hard, hit fast' - the statement originally adopted by Paul Ehrlich in 1913 to emphasize the importance of taking strong, early action against parasitic infections [34] - remains the strategy of choice with concentrationdependent agents, such as fluoroquinolones and aminoglycosides. The efficacy of these agents is related to the achievement of high $\mathrm{C}_{\max } / \mathrm{MIC}$ ratio $(>10)$ and $\mathrm{AUC} / \mathrm{MIC}$ ratio $(>100$ to 125) [35]. Accordingly, high dosage, short-course therapy regimens with a once daily administration schedule (Figure 3) may yield more rapid bacterial killing or prevention of resistance development [36-38].

An intriguing example comes from a recent clinical study that compared the efficacies of two schedule regimens of levofloxacin (750 mg every 24 hours for 5 days [ $n=76$ ] and $500 \mathrm{mg}$ every 24 hours for 10 days $[n=83]$ ) in the treatment of hospitalized patients with community-acquired pneumonia [37]. Clinical success rates among the two patient groups did not differ significantly, regardless of the severity of pneumonia (Pneumonia Severity Index class III or IV). Interestingly, however, the percentage of patients with resolution of some relevant symptoms (purulent sputum and fever) by day 3 of therapy was significantly higher among those who received $750 \mathrm{mg}$ every 24 hours (purulent sputum: $48.4 \%$ versus $27.5 \%[P=0.007]$; fever: $48.4 \%$ versus $34.0 \%[P=0.046])$. Accordingly, it may be speculated that high-dosage, shortcourse regimens with concentration-dependent antimicrobials may be especially useful in terms of shortening the time to resolution of symptoms in seriously ill patients. 
Figure 3

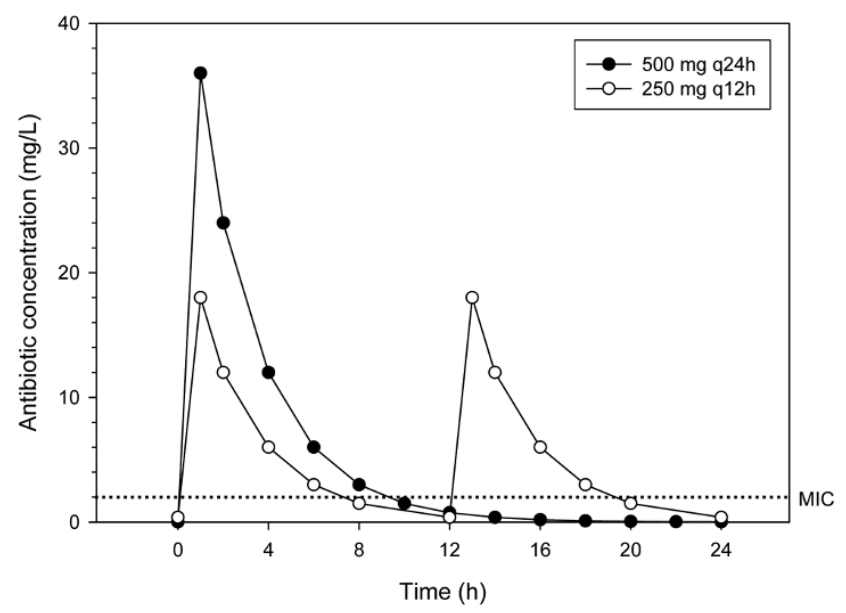

Pharmacodynamics of a concentration-dependent antimicrobial. Shown is a comparison of the simulated drug concentration profile of a concentration-dependent antimicrobial with an elimination half-life of 2 hours administered once daily or in two divided doses. Under the same total daily dose, once daily administration ensures higher $\mathrm{C}_{\max } / \mathrm{MIC}$ ratio in presence of equal AUC/MIC ratio. Dotted line refers to a MIC of $2 \mathrm{mg} / \mathrm{l}$. AUC, area under the plasma concentration-time curve; $\mathrm{C}_{\max }$, peak plasma concentration; MIC, minimum inhibitory concentration.

Likewise, for aminoglycosides once-daily administration is considered at least as efficacious as dosing three times a day [39]. This is unsurprising, considering that in some clinical studies $\mathrm{C}_{\max } / \mathrm{MIC}$ ratio was found to be the pharmacodynamic parameter most important to outcome [40]. Interestingly, in a prospective study conducted in 89 critically ill patients receiving a once-daily regimen of $7 \mathrm{mg} / \mathrm{kg}$ gentamycin or tobramycin [41], satisfactory $C_{\max } / \mathrm{MIC}$ ratios above 10 were observed in the majority of cases. However, in patients with glomerular hyperfiltration and with extensive burns over more than 15\% of their body surface area, higher than standard daily dosages of aminoglycosides may be needed to reach adequate $C_{\max }$ [42]. Additionally, once-daily dosing may potentially be less nephrotoxic. Among 54 patients randomly assigned to receive tobramycin once daily $(n=25)$ or in multiple daily doses $(n=29)$ for the treatment of suspected or documented Gram-negative infection, a significantly lower increase in urinary enzymes suggestive of nephrotoxicity ( $N$-acetyl- $\beta$-D-glucosaminidase and alanine aminopeptidase) was documented in the once-daily group, despite the administration of higher dosages [43].

\section{Time-dependent antibiotics}

In contrast to concentration-dependent agents, 'achieve the target quickly and maintain it' is the optimal strategy with time-dependent antibacterial agents, namely $\beta$-lactams, glycopeptides and oxazolidinones, whose efficacy in severely ill patients is related mainly to the maintenance of suprainhibitory concentrations. Indeed, the need for MIC coverage for $100 \%$ of the dosing interval with time-dependent antimicrobials is a matter of debate. Valid bacterial killing with $\beta$-lactams may occur with a $\mathrm{t}>\mathrm{MIC}$ of just a fraction of the dosing interval (20\% to $40 \%$ for carbapenems, $50 \%$ to $60 \%$ for penicillins, and $60 \%$ to $70 \%$ for cephalosporins) [11]. However, it should not be overlooked that bacterial regrowth may start when the concentration falls below the MIC [44], and that a higher probability of in vivo microbiological success has been demonstrated with a $>\mathrm{MIC}$ of $90 \%$ to $100 \%$ of the dosing interval [45]. Accordingly, it may reasonably be suggested that early attainment and maintenance of plasma trough concentration $\left(\mathrm{C}_{\mathrm{min}}\right)$ above the MIC should represent the goal of therapy in daily clinical practice for critically ill patients $[5,46]$. Indeed, the large inter-individual and intraindividual pharmacokinetic variability observed in these patients may result in unpredictable plasma concentrations $[45,47]$, such that TDM of plasma concentrations - whenever feasible - should be considered an invaluable tool for tailoring drug therapy in this context $[8,48]$. Furthermore, three stepup approaches may be considered with the aim of maximizing the efficacy of time-dependent antimicrobials under the same total daily dose in critically ill patients.

The first step is to consider multiple daily dosing. A Monte Carlo simulation study assessed the theoretical cumulative fractions of response with carbapenems, among others [49]. It showed that $500 \mathrm{mg}$ every 6 hours may be equivalent to $1 \mathrm{~g}$ every 8 hours both for imipenem and meropenem in terms of achieving bactericidal pharmacodynamic targets for the most relevant Gram-negative bacilli isolated from the ICU (Pseudomonas aeruginosa, Acinetobacter baumannii, Escherichia coli and Klebsiella spp.). These data confirm the previous findings of a retrospective analysis of a populationbased predictive model [50], which assessed the pharmacodynamics of meropenem in febrile neutropenic patients with bacteraemia. Accordingly, it may be speculated that, because it carries less risk for subtherapeutic drug concentrations, the strategy of increasing the frequency of dosing but with smaller doses ( $500 \mathrm{mg}$ every 6 hours) may help to reduce the burden of carbapenem usage. In turn, this might contain the spread of bacterial resistance due to antibiotic selective pressure.

Although multiple administration of time-dependent antimicrobials at standard daily dosage might be useful in clinically stable patients, this may not suffice in patients with glomerular hyperfiltration and/or with infections with borderline susceptible bacterial strains. An important option in such cases may be to shorten the dosing interval. Interestingly, a recent study analyzed imipenem plasma concentrations in 57 febrile neutropenic patients with a median $\mathrm{CL}_{\mathrm{Cr}}$ of $105 \mathrm{ml} /$ minute (range: 29 to $235 \mathrm{ml} /$ minute) [46]. It was predicted, by means of a population pharmacokinetic program, that the recommended regimen of $500 \mathrm{mg}$ every 6 hours might ensure optimal pharmacodynamic exposure against the most common pathogens, in terms of $\mathrm{C}_{\text {min }}>\mathrm{MIC}_{90}$, in only $53 \%$ of 
patients. However, when considering higher imipenem dosages ( $3 \mathrm{~g} /$ day) with the intent being to achieve a higher percentage of simulated patients with adequate imipenem $\mathrm{C}_{\min }$ in the presence of glomerular hyperfiltration, it was demonstrated that the strategy of shortening the time to redosing (500 mg every 4 hours) was much more effective than that of increasing single dosage amount ( $1 \mathrm{~g}$ every 8 hours).

Another, less expensive strategy in these cases may be the use of extended infusion, over 3 to 4 hours, of standard multiple daily dosing (Figure 4). By ensuring more sustained concentrations, this may increase the probability of successful clinical outcome [50,51]. The effectiveness of this approach was recently demonstrated for piperacillin-tazobactam in an interesting retrospective comparative study [51] that assessed the efficacy of two different schedule regimens (3.375 over 240 minutes every 8 hours $[n=102]$ versus 3.375 over 30 minutes every 6 to 8 hours $[n=92])$ for the treatment of $P$. aeruginosa infections. Among patients who were not critically ill (Acute Physiology and Chronic Health Evaluation [APACHE] II score <17) the 14-day mortality rate was not influenced by the administration schedule $(6.6 \%$ for extended infusion versus $3.7 \%$ for intermittent infusion; $P=0.5$ ), but among critically ill patients (APACHE II score $\geq 17$ ) it was significantly lower for those patients who received extended infusion therapy than for patients who received intermittent infusion therapy $(12.2 \%$ versus $31.6 \%$; $P=0.04)$. These findings strongly suggest that extended infusion of $\beta$-lactams may improve clinical outcome in critically ill patients with severe infections, and indicate that continuous infusion may be the best approach in terms of maximizing efficacy with time-dependent antimicrobials. Indeed, the stability of an antibiotic in solution at room temperature is an important consideration when choosing to administer time-dependent antibiotics by continuous infusion (Table 2). As a general rule, drugs that are stable at room temperature for only a few hours must be prepared fresh and changed regularly. This may be particularly relevant to the anti-pseudomonal carbapenems meropenem and imipenem [52]. In contrast, piperacillin/tazobactam, cefepime, ceftazidime and vancomycin are stable at room temperature for at least 24 hours [52,53].

The comparative efficacy of $\beta$-lactams administered by continuous versus intermittent infusion was recently assessed in three retrospective studies with the same design conducted by Lorente and coworkers. In the first study [54] the efficacy of $4 \mathrm{~g} /$ day meropenem by continuous infusion $(1 \mathrm{~g}$ over 360 minutes every 6 hours) versus intermittent infusion (1 $\mathrm{g}$ over 30 minutes every 6 hours) was assessed in patients with ventilator-associated pneumonia (VAP) due to Gramnegative bacilli [54]. Despite there being no significant differences between patient groups with regard to sex, age, APACHE II score at ICU admission, diagnosis, and responsible micro-organisms and their susceptibility to meropenem, the group receiving medication by continuous infusion

\section{Figure 4}

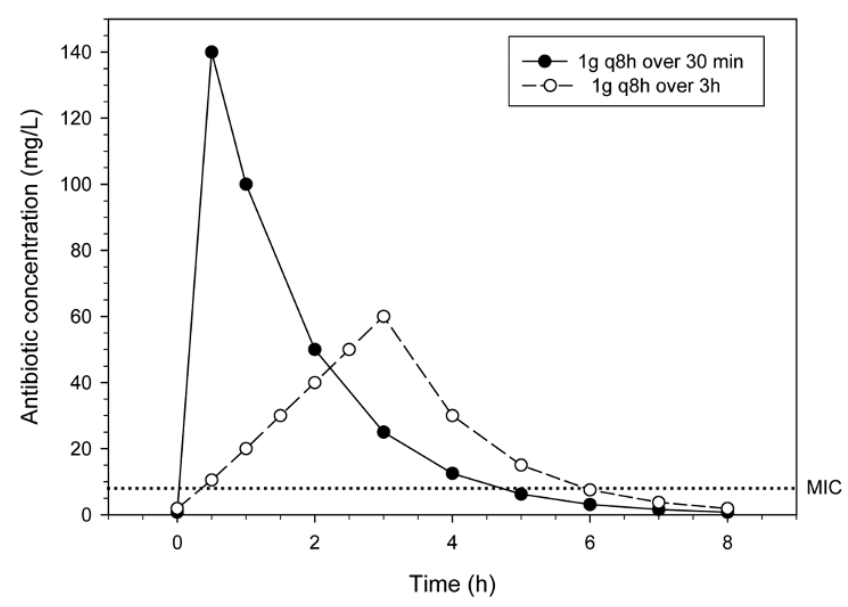

Pharmacodynamics of a time-dependent antimicrobial. Shown is a comparison of the simulated drug concentration profile of a timedependent anitmicrobial with an elimination half-life of 1 hour administered over 30 minutes or over 3 hours. The extended infusion time increases the time for which the antibiotic concentration exceeds the minimum inhibitory concentration ( $\mathrm{P}>\mathrm{MIC}$ ). Dotted line refers to a $\mathrm{MIC}$ of $8 \mathrm{mg} / \mathrm{l}$.

( $n=42)$ exhibited a greater clinical cure rate than did the group treated with intermittent infusion $(n=47)(90.47 \%$ versus 59.57\%; $P<0.001$ ). Of note, when clinical cure rates were considered in relation to meropenem susceptibility of bacterial isolates, the percentage difference between groups in positive outcome (in favour of continuous infusion) was more relevant in the presence of less susceptible microorganisms (MIC $\geq 0.50$ : $80.95 \%$ versus $29.41 \%[P=0.003]$; MIC 0.25 to $0.49: 100 \%$ versus $76.67 \%[P=0.03])$.

In the second retrospective study [55] the efficacy of $4 \mathrm{~g} /$ day ceftazidime by continuous infusion $(2 \mathrm{~g}$ over 720 minutes every 12 hours) versus intermittent infusion ( $2 \mathrm{~g}$ over 30 minutes every 12 hours) was assessed using the same study design in patients with VAP due to Gram-negative bacilli. Despite there being no significant differences between patient groups in baseline characteristics, the group receiving ceftazidime by continuous infusion $(n=56)$ exhibited a greater clinical cure rate than did the group treated with intermittent infusion ( $n=65$ ) (89.3\% versus $52.3 \% ; P<0.001)$. The percentage difference in positive clinical outcome (in favour of continuous infusion) was greater among patients with infection due to less susceptible micro-organisms (MIC $=8 \mathrm{mg} / \mathrm{l}: \quad 75 . \%$ versus $14.3 \% \quad[P=0.03] ; \mathrm{MIC}=4 \mathrm{mg} / \mathrm{l}: 90.0 \%$ versus $38.5 \% \quad[P=0.02] ; \quad \mathrm{MIC} \leq 2 \mathrm{mg} / \mathrm{l}: 92.1 \%$ versus $62.2 \%$ $[P<0.001])$.

In the third retrospective study [56] the efficacy of $16 / 2 \mathrm{~g} /$ day piperacillin/tazobactam by continuous infusion ( $4 / 0.5 \mathrm{~g}$ over 360 minutes every 6 hours) versus intermittent infusion 
Table 2

Stability of time-dependent antibiotics in solution for intravenous infusion

\begin{tabular}{lccl}
\hline Antibiotic & $\begin{array}{c}\text { Time of stability } \\
\text { at room } \\
\text { temperature } \\
\left(+25^{\circ} \mathrm{C} ; \text { hours }\right)\end{array}$ & $\begin{array}{c}\text { Maximum } \\
\text { concentration } \\
\text { tested } \\
(\mathrm{mg} / \mathrm{l})\end{array}$ & Solvent \\
\hline Piperacillin/tazobatam [52] & $>72$ & 128,000 & Sterile water for injection \\
Ceftazidime [52] & 24 & 120,000 & Sterile water for injection \\
Cefepime [52] & 13 & 50,000 & Sterile water for injection \\
Imipenem [52] & 3.30 & 8,000 & Sterile water for injection \\
Meropenem [52] & 5.15 & 64,000 & Sterile water for injection \\
Vancomycin [53] & $>696$ & $\mathrm{NA}$ & $\begin{array}{l}\text { Sterile water for injection, sodium chloride solution (0.9\%; } \mathrm{pH} 5.4), \\
\text { dextrose solution (5\%; } \mathrm{pH} 4.2)\end{array}$
\end{tabular}

Stability was defined as times during which antibiotic remains $>90 \%$ stable in solution. NA, not applicable.

(4/0.5 g over 30 minutes every 6 hours) was assessed using the same study design in patients with VAP due to Gramnegative bacilli. Once again, despite there being no relevant differences between patient groups with regard to baseline characteristics, the group receiving pipercillin/tazobactam by continuous infusion $(n=37)$ exhibited a greater clinical cure rate than did the group treated with intermittent infusion $(n=46)$ (89.2\% versus $56.5 \% ; P<0.001)$. In this last study, the percentage difference in positive clinical outcome (in favour of continuous infusion) became significantly larger only when patients presented with infection due to less susceptible micro-organisms ( $\mathrm{MIC}=4 \mathrm{mg} / \mathrm{l}$ : $90.0 \%$ versus $76.0 \% \quad[P=0.20] ; \mathrm{MIC}=8 \mathrm{mg} / \mathrm{l}: 88.9 \%$ versus $40 \%$ $[P=0.02] ; \mathrm{MIC}=16 \mathrm{mg} / \mathrm{l}: 87.5 \%$ versus $16.7 \%[P=0.02])$.

A recent prospective pharmacokinetic/pharmacodynamic study conducted in patients with VAP confirmed that continuous infusion may be helpful in providing adequate alveolar exposure with piperacillin/tazobactam, in terms of steadystate ELF concentrations exceeding the susceptibility breakpoint of $16 \mathrm{mg} / \mathrm{l}$ [57]. This was the case even when the standard $16 / 2 \mathrm{~g} /$ day dosage was administered to patients with normal renal function. Likewise, continuous infusion was recently advocated as a potentially useful tool for improving the efficacy of the standard vancomycin daily dose $(30 \mathrm{mg} / \mathrm{kg}$ ) in the treatment of methicillin-resistant Staphylococcus aureus infections due to micro-organisms with borderline susceptibility [58], thus avoiding the need for larger daily doses, which have been shown to increase the risk for nephrotoxicity [59]. In a retrospective study conducted in patients treated with vancomycin because of oxacillinresistant VAP, Rello and coworkers [13] demonstrated that vancomycin by continuous infusion was independently associated with lower mortality rates compared with intermittent infusion (25\% versus 54.2\%; $P=0.02)$. Continuous infusion may be the best way to maximize the time-dependent activity of vancomycin because, under the same daily dosage, it may achieve higher and more sustained concentrations at the infection site but without increasing the daily exposure in terms of AUC (Figure 5) [5,60-62]. That is why we recently developed a prospectively validated dosing nomogram to maximize the pharmacodynamics of vancomycin administered by continuous infusion [58]; the aim of the nomogram is to achieve plasma steady-state concentrations of 15 to $20 \mathrm{mg} / \mathrm{l}$ rapidly in critically ill patients. Interestingly, among 182 physicians who responded to a survey on antibiotic usage habits in Italian ICUs (proposed at a conference on anaesthesia and intensive care [SMART] held in May 2007 in Milan, Italy), 78\% indicated that they usually administered vancomycin by continuous infusion (Pea F, Viale $\mathrm{P}$, unpublished data).

In a recent meta-analysis of nine randomized controlled trials comparing continuous intravenous infusion with intermittent intravenous administration of the same antibiotic regimen [63], clinical failure was lower in patients receiving continuous infusion, albeit without statistical significance (pooled odds ratio $=0.73,95 \%$ confidence interval $=0.53$ to 1.01 ) However, in a subset of randomized controlled trials that used the same total daily antibiotic dose for both intervention arms, this difference was statistically significant (pooled odds ratio $=0.70,95 \%$ confidence interval $=0.50$ to 0.98 ; fixed and random effects models).

Although randomized clinical trials are clearly required to confirm these findings, and prospective trials are needed to address a management strategy based on TDM, it could reasonably be suggested that continuous infusion is a promising tool for improving clinical cure with time-dependent antimicrobials, especially among the critically ill. This may be more relevant in infections with borderline susceptible pathogens and/or in patients with glomerular hyperfiltration. Of note, it must be recalled that when choosing continuous infusion, an initial LD must always be administered, irrespective of the patient's renal function, in order to achieve therapeutically effective concentrations rapidly and to limit 


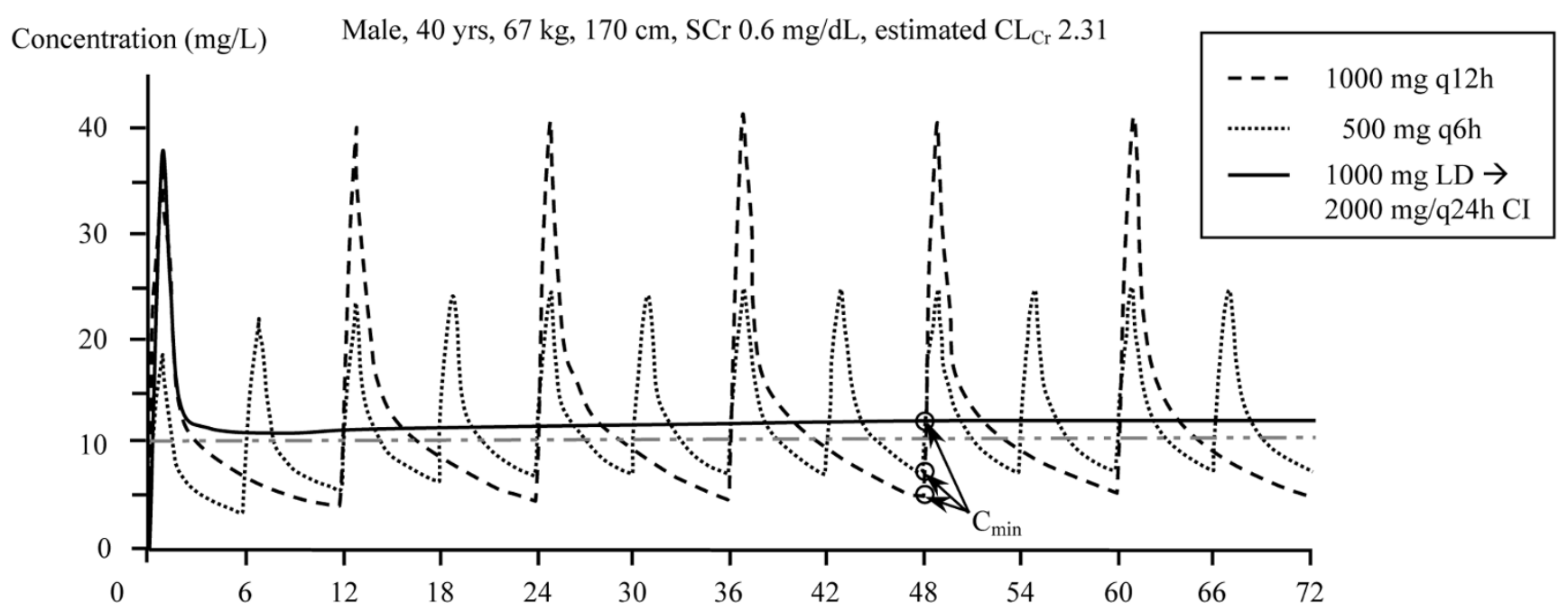

Time (hours)

Simulation of different administration schedules of $2 \mathrm{~g}$ daily vancomycin. Shown are simulated profiles of vancomycin daily plasma exposure achievable in a young male with normal renal function when administering the fixed $30 \mathrm{mg} / \mathrm{kg}$ per day dose separated into two or four intermittent infusions, or by continuous infusion (Cl) after loading (loading dose [LD]). Simulation was performed using a two-compartment linear model by means of the Abbottbase Pharmacokinetic Systems program (PKS; v 1.10) from Abbott Laboratories Diagnostics Division. The dotted/dashed line refers to $10 \mathrm{mg} / \mathrm{l}$. Reproduced with permission from Pea and coworkers [61]. $\mathrm{CL}_{\mathrm{Cr}}$, creatinine clearance; SCr, serum creatinine.

risk for underexposure during the first few hours of treatment, with continuous infusion starting immediately afterward. For a comprehensive review of the potential role of continuous infusion of time-dependent antimicrobials in the treatment of infections in critically ill patients, readers are referred to recent work reported by Roberts and coworkers [62].

\section{Antimicrobial therapy in patients undergoing continuous renal replacement therapy}

It is worth noting that appropriate dosing of antimicrobial agents in critically ill patients may be further complicated by the application of continuous renal replacement therapy (CRRT), especially when residual renal function coexists [64]. As a general rule (Table 3 ), drugs for which the kidney is the predominant site of clearance and that may be extracted by CRRT may need significant dosage increase as compared with the setting of renal failure or even with intermittent haemodialysis. This is usually the case for $\beta$-lactams, glycopeptides, aminoglycosides, levofloxacin and ciprofloxacin. Conversely, drugs that are not normally cleared via the renal route and that exhibit very low extraction during CRRT may need unmodified dosages in comparison with normal renal function, as in the case of linezolid and moxifloxacin. Clearly, TDM is invaluable in such cases.

\section{Conclusions}

Appropriate antibiotic therapy in patients with severe sepsis and septic shock should mean prompt achievement and maintenance of optimal exposure at the infection site with broad-spectrum antimicrobial agents administered in a timely manner. Once the causative pathogens have been identified and tested for in vitro susceptibility, subsequent deescalation of antimicrobial therapy should be applied whenever feasible. Appropriateness of treatment is rarely assessed in terms of adequate dosing schedule regimens. Inadequate dosing schedules may lead to suboptimal exposure at the infection site, increasing the risk for therapeutic failure or selection of resistant bacteria. However, administration of higher antibiotic doses than are required increases the risk for adverse events. Therefore, TDM of plasma concentrations should be encouraged whenever possible, because these concentrations are difficult to predict in critically ill patients, even when their renal function is estimated using different formulae. Indeed, infections mainly occur in tissue extracellular fluids, and it is the generally accepted view that - once steady-state pharmacokinetics are achieved - the unbound concentrations in plasma and extracellular fluids are similar, even in the most severely ill patients [65]. Therefore, assessment of antibiotic concentration in plasma is a good surrogate for estimating antibiotic concentration at the tissue infection site, provided that the unbound concentration is measured. However, in certain situations unbound concentrations at equilibrium may be lower in tissues than in plasma. This is the case when active efflux transport systems restrict tissue distribution [66], as observed in brain [67], or in the presence of drug degra- 


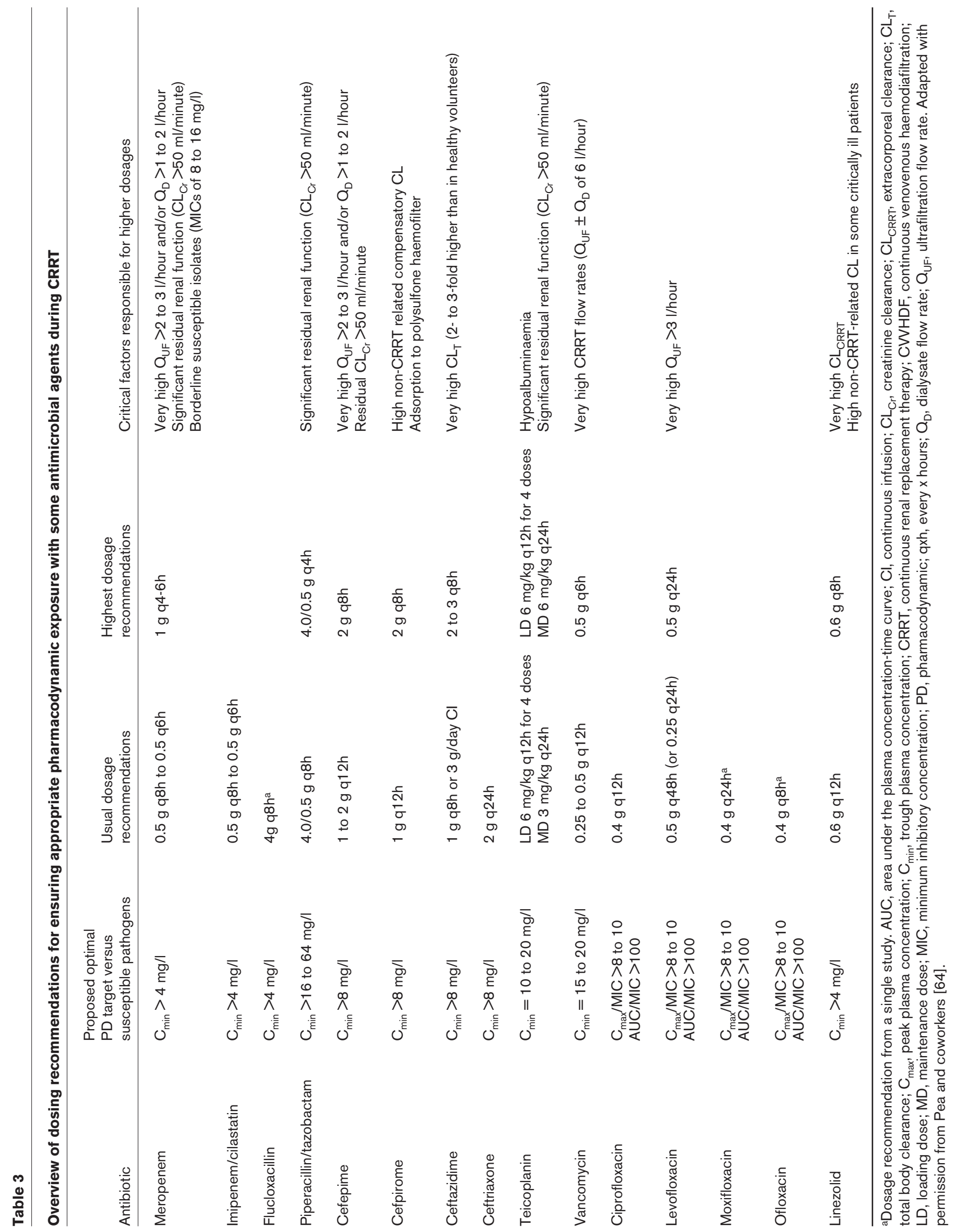


dation within tissues, such as in the peritoneal cavity of patients with severe secondary peritonitis $[14,68]$.

Unfortunately, clinical data in this area are still lacking, and much work remains to be done in this field before useful antibiotic regimen recommendations can be developed. Until such recommendations become available, the goal of appropriate antibiotic therapy must be pursued resolutely and with continuity, in view of the ongoing explosion of antibiotic-resistant infections that plague the ICU setting and of the continued decrease in new antibiotics emerging [69].

\section{Competing interests}

No sources of funding were used to assist in the preparation of this commentary. Federico Pea has been a consultant for Astellas, has been a consultant for and on the speakers' bureau for Pfizer and Sanofi-Aventis, and has also been on the speakers' bureau for Abbott, Bayer, Gilead, GlaxoSmithKline, Merck Sharp \& Dohme and Wyeth. Pierluigi Viale has been a consultant for, has received grant support from, and has been on the speakers' bureau for Astellas, Merck Sharp \& Dohme, Pfizer and Sanofi-Aventis, and has also received grant support from and been on the speakers' bureau for Bayer and GlaxoSmithKline. He has also been on the speakers' bureau for Abbott, Gilead and Wyeth.

\section{References}

1. Niederman MS: Use of broad-spectrum antimicrobials for the treatment of pneumonia in seriously ill patients: maximizing clinical outcomes and minimizing selection of resistant organisms. Clin Infect Dis 2006, 42(suppl 2):S72-S81.

2. Teixeira PJ, Seligman R, Hertz FT, Cruz DB, Fachel JM: Inadequate treatment of ventilator-associated pneumonia: risk factors and impact on outcomes. J Hosp Infect 2007, 65:361367.

3. Zilberberg MD, Shorr AF, Micek ST, Mody SH, Kollef MH: Antimicrobial therapy escalation and hospital mortality among patients with health-care-associated pneumonia: a singlecenter experience. Chest 2008, 134:963-968.

4. Davey PG, Marwick C: Appropriate vs. inappropriate antimicrobial therapy. Clin Microbiol Infect 2008, 14(suppl 3):15-21.

5. Pea F, Viale P: The antimicrobial therapy puzzle: could pharmacokinetic-pharmacodynamic relationships be helpful in addressing the issue of appropriate pneumonia treatment in critically ill patients? Clin Infect Dis 2006, 42:1764-1771.

6. Pea F, Viale P, Furlanut M: Antimicrobial therapy in critically ill patients: a review of pathophysiological conditions responsible for altered disposition and pharmacokinetic variability. Clin Pharmacokinet 2005, 44:1009-1034.

7. Tam VH, Gamez EA, Weston JS, Gerard LN, Larocco MT, Caeiro JP, Gentry LO, Garey KW: Outcomes of bacteremia due to Pseudomonas aeruginosa with reduced susceptibility to piperacillin-tazobactam: implications on the appropriateness of the resistance breakpoint. Clin Infect Dis 2008, 46:862-867.

8. Conil JM, Georges B, Mimoz O, Dieye E, Ruiz S, Cougot P, Samii K, Houin G, Saivin S: Influence of renal function on trough serum concentrations of piperacillin in intensive care unit patients. Intensive Care Med 2006, 32:2063-2066.

9. Roosendaal R, Bakker-Woudenberg IA, van den Berghe-van Raffe $\mathrm{M}$, Michel MF: Continuous versus intermittent administration of ceftazidime in experimental Klebsiella pneumoniae pneumonia in normal and leukopenic rats. Antimicrob Agents Chemother 1986, 30:403-408.

10. Mouton JW, Vinks AA: Continuous infusion of beta-lactams. Curr Opin Crit Care 2007, 13:598-606.

11. Drusano GL: Antimicrobial pharmacodynamics: critical interactions of 'bug and drug'. Nat Rev Microbiol 2004, 2:289-300.
12. Kim A, Sutherland CA, Kuti JL, Nicolau DP: Optimal dosing of piperacillin-tazobactam for the treatment of Pseudomonas aeruginosa infections: prolonged or continuous infusion? Pharmacotherapy 2007, 27:1490-1497.

13. Rello J, Sole-Violan J, Sa-Borges M, Garnacho-Montero J, Munoz E, Sirgo G, Olona M, Diaz E: Pneumonia caused by oxacillinresistant Staphylococcus aureus treated with glycopeptides. Crit Care Med 2005, 33:1983-1987.

14. Seguin P, Verdier MC, Chanavaz C, Engrand C, Laviolle B, Donnio PY, Malledant Y: Plasma and peritoneal concentration following continuous infusion of cefotaxime in patients with secondary peritonitis. J Antimicrob Chemother 2009, 63:564567.

15. Silverman JA, Mortin LI, Vanpraagh AD, Li T, Alder J: Inhibition of daptomycin by pulmonary surfactant: in vitro modeling and clinical impact. $J$ Infect Dis 2005, 191:2149-2152.

16. Dellinger RP, Levy MM, Carlet JM, Bion J, Parker MM, Jaeschke R, Reinhart K, Angus DC, Brun-Buisson C, Beale R, Calandra T, Dhainaut JF, Gerlach H, Harvey M, Marini JJ, Marshall J, Ranieri M, Ramsay G, Sevransky J, Thompson BT, Townsend S, Vender JS, Zimmerman JL, Vincent JL: Surviving Sepsis Campaign: international guidelines for management of severe sepsis and septic shock: 2008. Intensive Care Med 2008, 34:17-60.

17. Russell JA: Management of sepsis. N Engl J Med 2006, 355: 1699-1713.

18. Joukhadar C, Frossard M, Mayer BX, Brunner M, Klein N, Siostrzonek $\mathrm{P}$, Eichler HG, Muller M: Impaired target site penetration of beta-lactams may account for therapeutic failure in patients with septic shock. Crit Care Med 2001, 29:385-391.

19. Dorman T, Swoboda S, Zarfeshenfard F, Trentler B, Lipsett PA: Impact of altered aminoglycoside volume of distribution on the adequacy of a three milligram per kilogram loading dose. Critical Care Research Group. Surgery 1998, 124:73-78.

20. Pea F, Brollo L, Viale P, Pavan F, Furlanut M: Teicoplanin therapeutic drug monitoring in critically ill patients: a retrospective study emphasizing the importance of a loading dose. J Antimicrob Chemother 2003, 51:971-975.

21. Thallinger C, Buerger C, Plock N, Kljucar S, Wuenscher S, Sauermann R, Kloft C, Joukhadar C: Effect of severity of sepsis on tissue concentrations of linezolid. J Antimicrob Chemother 2008, 61:173-176.

22. Cockcroft DW, Gault MH: Prediction of creatinine clearance from serum creatinine. Nephron 1976, 16:31-41.

23. Herrera-Gutierrez ME, Seller-Perez G, Banderas-Bravo E, MunozBono J, Lebron-Gallardo M, Fernandez-Ortega JF: Replacement of 24-h creatinine clearance by $2-\mathrm{h}$ creatinine clearance in intensive care unit patients: a single-center study. Intensive Care Med 2007, 33:1900-1906.

24. Hoste EA, Damen J, Vanholder RC, Lameire NH, Delanghe JR, Van den Hauwe K, Colardyn FA: Assessment of renal function in recently admitted critically ill patients with normal serum creatinine. Nephrol Dial Transplant 2005, 20:747-753.

25. Martinez-Rodriguez JE, Barriga FJ, Santamaria J, Iranzo A, Pareja JA, Revilla M, dela Rosa CR: Nonconvulsive status epilepticus associated with cephalosporins in patients with renal failure. Am J Med 2001, 111:115-119.

26. Chatellier D, Jourdain M, Mangalaboyi J, Ader F, Chopin C, Derambure $\mathrm{P}$, Fourrier F: Cefepime-induced neurotoxicity: an underestimated complication of antibiotherapy in patients with acute renal failure. Intensive Care Med 2002, 28:214-217.

27. Sonck J, Laureys G, Verbeelen D: The neurotoxicity and safety of treatment with cefepime in patients with renal failure. Nephrol Dial Transplant 2008, 23:966-970.

28. Pea F, Furlanut M: Pharmacokinetic aspects of treating infections in the intensive care unit: focus on drug interactions. Clin Pharmacokinet 2001, 40:833-868.

29. Dailly E, Brun A, Kergueris MF, Victorri-Vignoli C, Milpied N, Jolliet $P$ : A simple formula for individualising ceftazidime dosage administered by continuous infusion in patients with haematological malignancies. Int J Antimicrob Agents 2006, 27:553556.

30. Fuster-Lluch O, Geronimo-Pardo M, Peyro-Garcia R, Lizan-Garcia M: Glomerular hyperfiltration and albuminuria in critically ill patients. Anaesth Intensive Care 2008, 36:674-680.

31. Pea F, Furlanut M, Viale $P$ : Is antimicrobial underexposure due to glomerular hyperfiltration a possible cause of increased mortality rate from bacterial infections in the critically ill 
patients? Anaesth Intensive Care 2009, 37:323-324

32. Yano R, Nakamura T, Tsukamoto H, Igarashi T, Goto N, Wakiya $Y$, Masada M: Variability in teicoplanin protein binding and its prediction using serum albumin concentrations. Ther Drug Monit 2007, 29:399-403.

33. Barbot A, Venisse N, Rayeh F, Bouquet S, Debaene B, Mimoz O: Pharmacokinetics and pharmacodynamics of sequential intravenous and subcutaneous teicoplanin in critically ill patients without vasopressors. Intensive Care Med 2003, 29:15281534.

34. Ehrlich P: Chemotherapeutics: scientific principles, methods and results. Lancet 1913, Il:445-451.

35. Preston SL, Drusano GL, Berman AL, Fowler CL, Chow AT, Dornseif B, Reichl V, Natarajan J, Wong FA, Corrado M: Levofloxacin population pharmacokinetics and creation of a demographic model for prediction of individual drug clearance in patients with serious community-acquired infection. Antimicrob Agents Chemother 1998, 42:1098-1104.

36. Grossman RF, Rotschafer JC, Tan JS: Antimicrobial treatment of lower respiratory tract infections in the hospital setting. Am $J$ Med 2005, 118(suppl 7A):29S-38S.

37. Shorr AF, Khashab MM, Xiang JX, Tennenberg AM, Kahn JB: Levofloxacin $750-\mathrm{mg}$ for 5 days for the treatment of hospitalized Fine Risk Class III/IV community-acquired pneumonia patients. Respir Med 2006, 100:2129-2136.

38. Boselli E, Breilh D, Rimmele T, Djabarouti S, Saux MC, Chassard $\mathrm{D}$, Allaouchiche B: Pharmacokinetics and intrapulmonary diffusion of levofloxacin in critically ill patients with severe community-acquired pneumonia. Crit Care Med 2005, 33:104-109.

39. Barza M, loannidis JP, Cappelleri JC, Lau J: Single or multiple daily doses of aminoglycosides: a meta-analysis. BMJ 1996, 312:338-345

40. Burkhardt O, Lehmann $\mathrm{C}$, Madabushi R, Kumar V, Derendorf H, Welte T: Once-daily tobramycin in cystic fibrosis: better for clinical outcome than thrice-daily tobramycin but more resistance development? J Antimicrob Chemother 2006, 58:822829.

41. Buijk SE, Mouton JW, Gyssens IC, Verbrugh HA, Bruining HA: Experience with a once-daily dosing program of aminoglycosides in critically ill patients. Intensive Care Med 2002, 28:936942.

42. Conil JM, Georges B, Breden A, Segonds C, Lavit M, Seguin T, Coley N, Samii K, Chabanon G, Houin G, Saivin S: Increased amikacin dosage requirements in burn patients receiving a once-daily regimen. Int J Antimicrob Agents 2006, 28:226-230.

43. Olsen KM, Rudis MI, Rebuck JA, Hara J, Gelmont D, Mehdian R, Nelson C, Rupp ME: Effect of once-daily dosing vs. multiple daily dosing of tobramycin on enzyme markers of nephrotoxicity. Crit Care Med 2004, 32:1678-1682.

44. Mouton JW, Vinks AA: Relationship between minimum inhibitory concentration and stationary concentration revisited: growth rates and minimum bactericidal concentrations. Clin Pharmacokinet 2005, 44:767-768.

45. Ariano RE, Nyhlen A, Donnelly JP, Sitar DS, Harding GK, Zelenitsky SA: Pharmacokinetics and pharmacodynamics of meropenem in febrile neutropenic patients with bacteremia. Ann Pharmacother 2005, 39:32-38.

46. Lamoth F, Buclin T, Csajka C, Pascual A, Calandra T, Marchetti O: Reassessment of recommended imipenem doses in febrile neutropenic patients with hematological malignancies. Antimicrob Agents Chemother 2009, 53:785-787.

47. Belzberg H, Zhu J, Cornwell EE, 3rd, Murray JA, Sava J, Salim A, Velmahos GC, Gill MA: Imipenem levels are not predictable in the critically ill patient. J Trauma 2004, 56:111-117.

48. Pea F, Bertolissi M, Di Silvestre A, Poz D, Giordano F, Furlanut M: TDM coupled with Bayesian forecasting should be considered an invaluable tool for optimizing vancomycin daily exposure in unstable critically ill patients. Int J Antimicrob Agents 2002, 20: 326-332.

49. DeRyke CA, Kuti JL, Nicolau DP: Pharmacodynamic target attainment of six beta-lactams and two fluoroquinolones against Pseudomonas aeruginosa, Acinetobacter baumannii, Escherichia coli, and Klebsiella species collected from United States intensive care units in 2004. Pharmacotherapy 2007, 27: 333-342.

50. Lomaestro BM, Drusano GL: Pharmacodynamic evaluation of extending the administration time of meropenem using a
Monte Carlo simulation. Antimicrob Agents Chemother 2005, 49:461-463.

51. Lodise TP Jr, Lomaestro B, Drusano GL: Piperacillin-tazobactam for Pseudomonas aeruginosa infection: clinical implications of an extended-infusion dosing strategy. Clin Infect Dis 2007, 44: 357-363.

52. Viaene $E$, Chanteux $H$, Servais $H$, Mingeot-Leclercq MP, Tulkens PM: Comparative stability studies of antipseudomonal betalactams for potential administration through portable elastomeric pumps (home therapy for cystic fibrosis patients) and motor-operated syringes (intensive care units). Antimicrob Agents Chemother 2002, 46:2327-2332.

53. Wood MJ, Lund R, Beavan M: Stability of vancomycin in plastic syringes measured by high-performance liquid chromatography. J Clin Pharm Ther 1995, 20:319-325.

54. Lorente L, Lorenzo L, Martin MM, Jimenez A, Mora ML: Meropenem by continuous versus intermittent infusion in ventilator-associated pneumonia due to gram-negative bacilli. Ann Pharmacother 2006, 40:219-223.

55. Lorente L, Jimenez A, Palmero S, Jimenez JJ, Iribarren JL, Santana $M$, Martin MM, Mora ML: Comparison of clinical cure rates in adults with ventilator-associated pneumonia treated with intravenous ceftazidime administered by continuous or intermittent infusion: a retrospective, nonrandomized, open-label, historical chart review. Clin Ther 2007, 29:2433-2439.

56. Lorente L, Jimenez A, Martin MM, Iribarren JL, Jimenez JJ, Mora $M L$ : Clinical cure of ventilator-associated pneumonia treated with piperacillin/tazobactam administered by continuous or intermittent infusion. Int J Antimicrob Agents 2009, 33:464468.

57. Boselli E, Breilh D, Rimmele T, Guillaume C, Xuereb F, Saux MC, Bouvet L, Chassard D, Allaouchiche B: Alveolar concentrations of piperacillin/tazobactam administered in continuous infusion to patients with ventilator-associated pneumonia. Crit Care Med 2008, 36:1500-1506.

58. Pea F, Furlanut M, Negri C, Pavan F, Crapis M, Cristini F, Viale P: Prospectively validated dosing nomograms for maximizing the pharmacodynamics of vancomycin administered by continuous infusion in the critically ill patients. Antimicrob Agents Chemother 2009, 53:1863-1867.

59. Lodise TP, Lomaestro B, Graves J, Drusano GL: Larger vancomycin doses (at least four grams per day) are associated with an increased incidence of nephrotoxicity. Antimicrob Agents Chemother 2008, 52:1330-1336.

60. Byl B, Jacobs F, Wallemacq P, Rossi C, de Francquen P, Cappello M, Leal T, Thys JP: Vancomycin penetration of uninfected pleural fluid exudate after continuous or intermittent infusion. Antimicrob Agents Chemother 2003, 47:2015-2017.

61. Pea F, Viale P: Should the currently recommended twice-daily dosing still be considered the most appropriate regimen for treating MRSA ventilator-associated pneumonia with vancomycin? Clin Pharmacokinet 2008, 47:147-152.

62. Roberts JA, Lipman J, Blot S, Rello J: Better outcomes through continuous infusion of time-dependent antibiotics to critically ill patients? Curr Opin Crit Care 2008, 14:390-396.

63. Kasiakou SK, Sermaides GJ, Michalopoulos A, Soteriades ES, Falagas ME: Continuous versus intermittent intravenous administration of antibiotics: a meta-analysis of randomised controlled trials. Lancet Infect Dis 2005, 5:581-589.

64. Pea F, Viale P, Pavan F, Furlanut M: Pharmacokinetic considerations for antimicrobial therapy in patients receiving renal replacement therapy. Clin Pharmacokinet 2007, 46:997-1038.

65. Dahyot C, Marchand S, Bodin M, Debeane B, Mimoz O, Couet W: Application of basic pharmacokinetic concepts to analysis of microdialysis data: illustration with imipenem muscle distribution. Clin Pharmacokinet 2008, 47:181-189.

66. Hammarlund-Udenaes M, Paalzow LK, de Lange EC: Drug equilibration across the blood-brain barrier: pharmacokinetic considerations based on the microdialysis method. Pharm Res 1997, 14:128-134.

67. Chenel M, Marchand S, Dupuis A, Lamarche I, Paquereau J, Pariat C, Couet W: Simultaneous central nervous system distribution and pharmacokinetic-pharmacodynamic modelling of the electroencephalogram effect of norfloxacin administered at a convulsant dose in rats. $\mathrm{Br} J \mathrm{Pharmaco} / 2004,142: 323-330$.

68. Karjagin J, Lefeuvre S, Oselin K, Kipper K, Marchand S, Tikkerberi A, Starkopf J, Couet W, Sawchuk RJ: Pharmacokinetics of 
meropenem determined by microdialysis in the peritoneal fluid of patients with severe peritonitis associated with septic shock. Clin Pharmacol Ther 2008, 83:452-459.

69. Spellberg B, Guidos R, Gilbert D, Bradley J, Boucher HW, Scheld WM, Bartlett JG, Edwards J Jr: The epidemic of antibiotic-resistant infections: a call to action for the medical community from the Infectious Diseases Society of America. Clin Infect Dis 2008, 46:155-164.

70. Pea F, Viale $P$, Damiani D, Pavan F, Cristini F, Fanin R, Furlanut M: Ceftazidime in acute myeloid leukemia patients with febrile neutropenia: helpfulness of continuous intravenous infusion in maximizing pharmacodynamic exposure. Antimicrob Agents Chemother 2005, 49:3550-3553.

71. Boselli E, Breilh D, Duflo F, Saux MC, Debon R, Chassard D, Allaouchiche B: Steady-state plasma and intrapulmonary concentrations of cefepime administered in continuous infusion in critically ill patients with severe nosocomial pneumonia. Crit Care Med 2003, 31:2102-2106.

72. Nicasio AM, Ariano RE, Zelenitsky SA, Kim A, Crandon JL, Kuti JL, Nicolau DP: Population pharmacokinetics of high-dose, prolonged-infusion cefepime in adult critically-ill patients with ventilator associated pneumonia. Antimicrob Agents Chemother 2009, 53:1476-1481.

73. Sakka SG, Glauner AK, Bulitta JB, Kinzig-Schippers M, Pfister W, Drusano GL, Sorgel F: Population pharmacokinetics and pharmacodynamics of continuous versus short-term infusion of imipenem-cilastatin in critically ill patients in a randomized, controlled trial. Antimicrob Agents Chemother 2007, 51:33043310.

74. Rea RS, Capitano B, Bies R, Bigos KL, Smith R, Lee H: Suboptimal aminoglycoside dosing in critically ill patients. Ther Drug Monit 2008, 30:674-681.

75. American Thoracic Society, Infectious Diseases Society of America: Guidelines for the management of adults with hospital-acquired, ventilator-associated, and healthcare-associated pneumonia. Am J Respir Crit Care Med 2005, 171:388-416.

76. Romano S, Fdez de Gatta MM, Calvo MV, Caballero D, Dominguez-Gil A, Lanao JM: Population pharmacokinetics of amikacin in patients with haematological malignancies. J Antimicrob Chemother 1999, 44:235-242.

77. Lipman J, Scribante J, Gous AG, Hon H, Tshukutsoane S: Pharmacokinetic profiles of high-dose intravenous ciprofloxacin in severe sepsis. The Baragwanath Ciprofloxacin Study Group. Antimicrob Agents Chemother 1998, 42:2235-2239.

78. Pea F, Poz D, Viale P, Pavan F, Furlanut M: Which reliable pharmacodynamic breakpoint should be advised for ciprofloxacin monotherapy in the hospital setting? A TDM-based retrospective perspective. J Antimicrob Chemother 2006, 58:380-386.

79. Conil JM, Georges B, de Lussy A, Khachman D, Seguin T, Ruiz S, Cougot $P$, Fourcade O, Houin G, Saivin S: Ciprofloxacin use in critically ill patients: pharmacokinetic and pharmacodynamic approaches. Int J Antimicrob Agents 2008, 32:505-510.

80. Pea F, Di Qual E, Cusenza A, Brollo L, Baldassarre M, Furlanut M: Pharmacokinetics and pharmacodynamics of intravenous levofloxacin in patients with early-onset ventilator-associated pneumonia. Clin Pharmacokinet 2003, 42:589-598.

81. Mimoz O, Rolland D, Adoun M, Marchand S, Breilh D, Brumpt I, Debaene B, Couet W: Steady-state trough serum and epithelial lining fluid concentrations of teicoplanin $12 \mathrm{mg} / \mathrm{kg}$ per day in patients with ventilator-associated pneumonia. Intensive Care Med 2006, 32:775-779.

82. Pea F, Viale P, Candoni A, Pavan F, Pagani L, Damiani D, Casini $M$, Furlanut M: Teicoplanin in patients with acute leukaemia and febrile neutropenia: a special population benefiting from higher dosages. Clin Pharmacokinet 2004, 43:405-415.

83. Pea F, Viale P, Pavan F, Tavio M, Poz D, Beltrame A, Furlanut M: The effect of multifactorial, multidisciplinary educational interventions on appropriate use of teicoplanin. Int J Antimicrob Agents 2006, 27:344-350.

84. Clinical Pharmacology. Gold Standard Multimedia, v 2.31.

Tampa, FL: Gold Standard Inc., Elsevier; 2009. 